\title{
Article
}

\section{Assessment of Food Safety Knowledge, Attitudes and Practices among Street Food Vendors and Consumers' Perceptions of Street Food Vending in Maseru Lesotho}

\author{
Pontso Letuka ${ }^{1}$, Jane Nkhebenyane ${ }^{1, *}$ and Oriel Thekisoe ${ }^{2}$ \\ 1 Central University of Technology, Department of Life Science; letlotloletuka@gmail.com \\ 2 North- West University; oriel.thekisoe@nwu.ac.za \\ * Correspondence: snkheben@cut.ac.za; Tel.: +27 760882642
}

\begin{abstract}
Street vended foods are ready-to-eat food and beverages prepared and/ or sold in the streets. This trade provides for $85-99 \%$ of total employment in most African countries and $50 \%$ or more is constituted by women. The preparation of street vended foods is normally under unsatisfactory conditions and these may lead to the contamination of food. This descriptive survey was conducted in Maseru around the taxi ranks amongst 141 participants ( 48 food handlers and 93 consumers) using a semi structured questionnaire, open ended questionnaire and observation checklist. Majority of the food handlers were females $(n=35,60 \%)$ and males constituted only $(n=23$, $40 \%$ ). On average the vendor population that participated in this study was considered to have poor knowledge of food safety since they scored $49 \% \pm 11$. With regard to the consumers, $63 \%$ were males and $37 \%$ were females, and only $6 \%$ reported that they never buy street vended foods mainly due to the food safety issues and hygiene. Based on the results of this study, it is thus recommended that educational interventions be implemented. The observation study showed that they also operated under unhygienic conditions and 95\% of food handlers had the incorrect knowledge that washing utensils with detergent leaves them free of contamination. Regarding the consumer perceptions, they highlighted that the trade has the potential to grow and be profitable on condition that hygiene is emphasized and infrastructure improved so as to provide safe quality food.
\end{abstract}

Keywords: street vendors; consumers; food safety; knowledge; attitudes; practices

\section{Introduction}

"Street vended foods are described as ready-to-eat foods and beverages that are prepared and/or sold by vendors and hawkers on the streets or similar public places [1]. Good food and personal hygiene are a prerequisite for proper food handling and food safety. Food borne illnesses have devastating effects on public health and also impact negatively on the socioeconomic status of countries globally.

Presently, food poisoning is still a persisting and common problem globally that results in morbidity and significant mortality [2]. It has been reported that people who indulge in the consumption of street foods sometimes suffer from food borne diseases like cholera, diarrhea, typhoid fever and gastroenteritis [1]. Contamination of food by various pathogens is facilitated by various factors including temperature, storage and relative humidity surrounding the food [3]. It is in this regard that optimal hygiene is a critical component to observe during food handling and storage.

Unhygienic practices during food preparation and storage generates conditions that allow for the growth and transmission of food-borne pathogens and other microorganisms which may cause food poisoning [4]. Moreover, many food borne diseases and outbreaks have been attributed to 
infected food handlers and their unhygienic food handling practices [5]. In an attempt to mitigate this problem, the government of Lesotho requires that food handlers be tested for any contagious diseases before they are allowed to work on food premises. However, food handlers can also assist in the control of food poisoning incidences through good levels of knowledge, attitudes and practices since they are directly in involved in food handling [4].

Knowledge has been described by [6] as "a complex process of remembering, relating, or judging an idea or abstract phenomenon". To further elaborate, [7], stated that a general consensus was reached by authors that good levels of food safety knowledge among food handlers and putting such knowledge effectively into practice is invaluable in ensuring safe food production in any food establishment. According to Jain [8] and Campbell [9] attitudes involve the evaluation concepts associated with the way people think, feel and behave. Additionally it comprises of the cognitive-consistency theories, learning theories, functional theories and social judgment theories which basically imply what you know, how you feel and what you do [10]. With 70\% of confirmed food poisoning outbreaks being associated with food cooked outside [11], it is imperative for food handlers to undergo food safety training and increase their knowledge on food safety.

The aim of this study was to assess food safety knowledge and hygiene practices of street food vendors and the general perceptions of consumers about street vended food in Maseru Lesotho.

\section{Materials and Methods}

The ethical clearance was obtained from the Ministry of Health in Lesotho (id 97-2017) and the Central University of Lesotho, while informed consents were obtained from the participants

\subsection{Sample collection}

\subsubsection{Food Handler questionnaire}

The food handling and hygiene practices of food handlers $(n=58)$ were assessed by utilizing a descriptive survey and observation checklist. The vendors were randomly selected in order to avoid bias and no particular order was followed when choosing participants. All questionnaires were administered by the researcher in Sesotho language.

The questionnaire used in this study was derived from the one that has been used in previous studies with slight modifications $[5,6]$. The questionnaire was designed to analyze the four constructs namely: knowledge, attitudes, practices and demographic characteristics of the street food handlers

The demographics section of the questionnaire included age, gender, education level and food safety training. The food safety knowledge section aimed at finding out the food handler's knowledge on food pathogens, good hygiene and food handling practices, high risk groups and food-borne illnesses. This section comprised of 18 questions with the option of three possible answers "yes", "no" and "don't know". Each correct response was awarded one point while zero was awarded for an incorrect or "don't know" response. Food handlers with any score below 50\% were considered to have poor knowledge of food safety, whilst those with anything between 50\% and $75 \%$ were considered to have average knowledge and those with scores above $75 \%$ were considered to have good food safety knowledge The same scoring strategy was applied for the food safety attitudes questionnaire and this consisted of 16 questions.

With regard to the food safety practice section, 11 questions were asked regarding food handlers' behaviour with options of "yes" and "no" being possible answers. In this section points were awarded on a basis of whether the food handler's actions were correct or not. Additionally, one point was allocated for good practice and zero point was allocated for bad practice. 
11 of 11

\subsubsection{Consumer Questionnaire}

A different questionnaire was utilized for assessing perceptions and experiences of consumers with regard to street vended foods. Selected consumers $(n=93)$ were randomly chosen from high school and university students, taxi drivers, people who work and live around the street food vending areas.

\subsubsection{Observation checklist}

The checklist that was used in this study has been adapted and modified from previous studies $[12,6]$. The first part of the checklist was about demographic characteristics and this included location of the stall, age and gender of the vendor, education level and food safety training. The other part focused on 5 important aspects and these were1) the facilities, 2) environment around the stall, 3) personal hygiene 4) food storage and 5) cooking utensils.

\section{Data analysis}

Data was captured electronically by the researcher using Microsoft Excel. Any further analysis was done by a statistician using SAS Version 9.2. Descriptive statistics namely, frequencies and percentages were calculated for categorical data and means and standard deviations or medians and percentiles were calculated for numerical data. Correlation analysis was used to investigate the relationship between variables. Analytical statistics namely the Shapiro-Wilk Test was used to test for normality, the independent T-test or ANOVA was used to test for mean differences among groups, and the Mann-Whitney U-test or Kruskal-Wallis test was used to test for median differences among groups. A significance level $(\alpha)$ of 0.05 was used.

\section{Results and discussion}

\subsection{Demographic characteristics}

The majority of the participants were females $(n=35,60 \%)$, and males constituted only $(n=23$, $40 \%$ ) as depicted in Table 1 below. The mean age of all the respondents who agreed to give their age $(n=55)$ was $(36 \pm 10)$, while other food handlers $(n=3)$ were unwilling to provide their age and the information was recorded as such. Less than half of the f food handlers $(n=23,40 \%)$ had food safety training while $(n=35,60 \%)$ had none. Additionally, $(n=39,67 \%)$ had high school education, while $(n=14,24 \%)$ had elementary education. Lastly, $(n=3,5 \%)$ had higher/tertiary education and $(n=2,3 \%)$ were illiterate

Table 1. Demographic characteristics of food handlers

\begin{tabular}{lll}
\hline \multicolumn{1}{c}{ CHARACTERISTICS } & NUMBER & MEAN AND STD DEVIATION \\
\hline GENDER & $23(39.66 \%)$ & \\
Male & $35(60.34 \%)$ & $36 \pm 10$ \\
Female & & \\
AGE & & \\
FOOD SAFETY TRAINING & $23(39.66 \%)$ \\
Yes & $35(60.34 \%)$ \\
No & $14(24.14 \%)$ \\
EDUCATION LEVEL & $39(67.24 \%)$ \\
Elementary School & $3(5.1 \%)$ \\
High school & $2(3.45 \%)$ \\
Higher education & \\
Illiterate & \\
\hline
\end{tabular}




\subsection{Food safety knowledge}

The results of food handler knowledge are shown in Table 2 below. On average, the vendor population used in this study was considered to have poor knowledge since they scored $49 \% \pm 11$. All food handlers exhibited good knowledge of general sanitary practices such as regular hand washing during work (100\% correct answers), while the majority $(84 \%)$ had knowledge on proper cleaning and sanitization of utensils However, only (3\%) of the respondents had the knowledge that washing utensils with detergent does not necessarily leave them free of contamination. About 95\% of respondents had poor understanding of foodborne disease transmission on high risk groups. Moreover, about $64 \%$ of the respondents seemed to know that typhoid fever is transmitted by food. About (64\%) was recorded for participants who said HIV/AIDS could be transmitted by food.

Table 2. Food safety knowledge questionnaire

\begin{tabular}{|c|c|c|c|}
\hline \multirow{2}{*}{ QUESTIONS } & \multicolumn{3}{|c|}{ RESPONSE (\%) } \\
\hline & CORRECT & INCORRECT & DON'T KNOW \\
\hline $\begin{array}{l}\text { Washing hands before work reduces the risk of food } \\
\text { contamination }\end{array}$ & $58(100 \%)$ & $0(0 \%)$ & $0(0 \%)$ \\
\hline $\begin{array}{l}\text { Using gloves while handling food reduces the risk of food } \\
\text { contamination }\end{array}$ & $28(48 \%)$ & $11(19 \%)$ & $19(32 \%)$ \\
\hline $\begin{array}{l}\text { Proper cleaning and sanitation of utensils increases the risk } \\
\text { of contamination }\end{array}$ & $49(84 \%)$ & $7(12 \%)$ & $2(3 \%)$ \\
\hline $\begin{array}{l}\text { Eating and drinking during food preparation increases the } \\
\text { risk of food contamination }\end{array}$ & $30(52 \%)$ & $20(34 \%)$ & $8(14 \%)$ \\
\hline $\begin{array}{l}\text { Preparing food in advance reduces the risk of food } \\
\text { contamination }\end{array}$ & $36(62 \%)$ & $12(21 \%)$ & $10(17 \%)$ \\
\hline Reheating cooked food can contribute to food contamination & $14(24 \%)$ & $33(57 \%)$ & $11(19 \%)$ \\
\hline $\begin{array}{l}\text { Washing utensils with detergent leaves them free of } \\
\text { contamination }\end{array}$ & $2(3 \%)$ & $55(95 \%)$ & $1(2 \%)$ \\
\hline $\begin{array}{l}\text { Children, healthy adults, pregnant women and the elderly } \\
\text { are at equal risk for food contamination }\end{array}$ & $3(5 \%)$ & $50(86 \%)$ & $5(9 \%)$ \\
\hline Typhoid fever can be transmitted by food & $37(64 \%)$ & $10(17 \%)$ & $11(19 \%)$ \\
\hline HIVIAIDS can be transmitted by food & $37(64 \%)$ & $13(22 \%)$ & $8(14 \%)$ \\
\hline Bloody diarrhea can be transmitted by food & $40(74 \%)$ & $9(16 \%)$ & $9(16 \%)$ \\
\hline $\begin{array}{l}\text { Abortion in pregnant women can be induced by foodborne } \\
\text { diseases }\end{array}$ & $43(74 \%)$ & $2(3 \%)$ & $13(22 \%)$ \\
\hline Salmonella is among foodborne pathogens & $1(2 \%)$ & $0(0 \%)$ & $57(98 \%)$ \\
\hline Hepatitis $A$ is among foodborne pathogens & $2(3 \%)$ & $1(2 \%)$ & $55(95 \%)$ \\
\hline Staphylococcus is among foodborne pathogens & $1(2 \%)$ & $0(0 \%)$ & $57(98 \%)$ \\
\hline Can swollen cans contain microorganisms & $53(91 \%)$ & $0(0 \%)$ & $5(9 \%)$ \\
\hline $\begin{array}{l}\text { Microbes can be found on the skin, nose and mouth of } \\
\text { healthy individuals }\end{array}$ & $24(41 \%)$ & $13(22 \%)$ & $21(36 \%)$ \\
\hline $\begin{array}{l}\text { During an infectious disease of the skin, it is necessary to } \\
\text { take leave from work }\end{array}$ & $55(95 \%)$ & $2(3 \%)$ & $1(2 \%)$ \\
\hline
\end{tabular}

The effects of demographic characteristics of the food handlers regarding their knowledge of food safety were assessed. The mean values from both genders were compared, male and female (51 \pm 13 and $47 \pm 10$ respectively), $\mathrm{p}=0.3281$, therefore gender did not have an effect on the knowledge of the food handlers regarding food safety. There was a weak positive correlation $(r=0.11684)$ between age and knowledge, thus age did not have an effect on knowledge ( $p=0.3956)$. An ANOVA test was also done to compare the mean scores of education level of the food handlers; illiterate (36 \pm 20$)$, elementary school $(48 \pm 12)$, high school $(49 \pm 11)$ and higher education (59 \pm 6$), p=0.1638$, therefore education level had no effect on knowledge of this group. For the comparison of food safety training means $(\mathrm{no}=46 \pm 12$, yes $=54 \pm 9)$ an independent T-test was employed and $(\mathrm{p}=0.0040)$, thus showing that food safety training did have an effect on the food handlers' knowledge on food safety.

\subsection{Food safety attitudes questionnaire}

Table 3 below depicts the results of the food safety attitudes questionnaire. About $84 \%$ of the food handlers agreed that thoroughly cooked food is free from contamination while $95 \%$ agreed that 
foodborne diseases can be prevented by proper hand hygiene. Additionally, regarding the personal hygiene aspect, more than half of the respondents mentioned that wearing masks, gloves and caps is an important practice that can reduce the contamination of food (i.e. $76 \%, 67 \%$ and $98 \%$ respectively). The results are similar to that of Akabanda (2017) wherein $60 \%$ of the food handlers indicated that the use of caps, masks and gloves can minimize the risk of contamination. However, only about $55 \%$ of the respondents had a positive attitude towards proper storage of cleaning products/chemicals and food products. A similar finding was mentioned by Kunadu et al., [13] where $93.9 \%$ of the respondents had a good attitude towards proper chemical storage.

Table 3. Food safety attitudes questionnaire

\begin{tabular}{|c|c|c|c|}
\hline QUESTIONS & RESPONSE & & \\
\hline & CORRECT & INCORRECT & $\begin{array}{l}D O N^{\prime} T \\
\text { KNOW }\end{array}$ \\
\hline Thoroughly cooked food are free from contamination & $49(84 \%)$ & $4(7 \%)$ & $5(9 \%)$ \\
\hline Proper hand hygiene can prevent foodborne diseases & $55(95 \%)$ & $2(3 \%)$ & $1(2 \%)$ \\
\hline $\begin{array}{l}\text { Can a closed can/jar of cleaning product be stored together with closed } \\
\text { cans/jars of food products }\end{array}$ & $32(55 \%)$ & $22(38 \%)$ & $4(7 \%)$ \\
\hline $\begin{array}{l}\text { Raw and cooked food should be kept separately to reduce the risk for } \\
\text { food contamination }\end{array}$ & $57(98 \%)$ & $1(2 \%)$ & $0(0 \%)$ \\
\hline $\begin{array}{l}\text { It is necessary to check the temperature of refrigerators/freezers } \\
\text { periodically to reduce the reduce the risk for food contamination }\end{array}$ & $55(95 \%)$ & $1(2 \%)$ & $2(3 \%)$ \\
\hline Defrosted foods can be refrozen & $42(72 \%)$ & $9(16 \%)$ & $7(12 \%)$ \\
\hline $\begin{array}{l}\text { The health status of food handlers should be evaluated before } \\
\text { employment }\end{array}$ & $57(98 \%)$ & $1(2 \%)$ & $0(0 \%)$ \\
\hline The best way to thaw meat is in a bowl of cold water & $42(72 \%)$ & $14(24 \%)$ & $2(3 \%)$ \\
\hline $\begin{array}{l}\text { Wearing masks is an important practice to reduce the risk for food } \\
\text { contamination }\end{array}$ & $44(76 \%)$ & $9(16 \%)$ & $5(9 \%)$ \\
\hline $\begin{array}{l}\text { Wearing gloves is an important practice to reduce the risk for food } \\
\text { contamination }\end{array}$ & $39(67 \%)$ & $11(19 \%)$ & $8(14 \%)$ \\
\hline $\begin{array}{l}\text { Wearing caps is an important practice to reduce the risk for food } \\
\text { contamination }\end{array}$ & $57(98 \%)$ & $1(2 \%)$ & $0(0 \%)$ \\
\hline The ideal place to store raw meat in refrigerator is in the bottom shelf & $49(84 \%)$ & $2(3 \%)$ & $7(12 \%)$ \\
\hline Eggs must be washed after purchase & $12(21 \%)$ & $35(60 \%)$ & $11(19 \%)$ \\
\hline Dish towels can be a source of contamination & $56(97 \%)$ & $1(2 \%)$ & $1(2 \%)$ \\
\hline $\begin{array}{l}\text { Knives and cutting boards should be properly sanitized to prevent cross } \\
\text { contamination }\end{array}$ & $58(100 \%)$ & $0(0 \%)$ & $0(0 \%)$ \\
\hline $\begin{array}{l}\text { Food handlers who have abrasions or cuts on their hands should not } \\
\text { touch food without gloves }\end{array}$ & $53(91 \%)$ & $3(5 \%)$ & $2(3 \%)$ \\
\hline
\end{tabular}

\subsection{Food safety practices}

Table 4 below depicts the food safety practices of street food handlers, All the vendors (100\%) reported that they did not use gloves when distributing unwrapped food. About (64\%) of the vendors stated that they use aprons while working and only (9\%) used masks when necessary. Furthermore, $(25 \%)$ of the vendors reported that they wear nail polish while also handling food, and all the respondents $(100 \%)$ reported that they use sanitizer cleaning utensils while none reported the use of such for cleaning fruits. Almost all the vendors (98\%) prepared their food in advance and $79 \%$ adequately cleaned storage areas for safe keep of new products. About $84 \%$ of the vendors stated that they check expiry dates of perishable foods after delivery or before purchase. It has been noted by Avanza et al [14] that good knowledge does not necessarily influence good practice, and this was concluded after observing that food vendors sometimes compromised on food safety due to financial burdens. Furthermore, Clayton et al., [15] mentioned that $63 \%$ of the food handlers who exhibited knowledge in food safety did not necessarily show corresponding positive behavior towards food safety practices. This further attests to the fact that food handlers do not automatically practice food safety procedures during food handling and preparation although they may provide answers that imply good food safety knowledge. 
Table 4. Food safety practices questionnaire

\begin{tabular}{lll}
\hline \multirow{2}{*}{ QUESTIONS } & \multicolumn{2}{l}{ RESPONSE(\%) } \\
\cline { 2 - 3 } Do you use gloves during the distribution of unpackaged foods? if not, go to question 3 & $0(0 \%)$ & $58(100 \%)$ \\
\cline { 2 - 3 } Do you wash your hands properly before or after using gloves? & $0(0 \%)$ & $0(0 \%)$ \\
Do you wear an apron while working? & $37(64 \%)$ & $21(36 \%)$ \\
Do you wear a mask when you distribute unwrapped foods? & $5(9 \%)$ & $53(91 \%)$ \\
Do you eat or drink during work hours? & $29(50 \%)$ & $29(50 \%)$ \\
Do you wear nail polish when handling food? & $14(25 \%)$ & $43(75 \%)$ \\
Do you prepare meals in advance (i.e., from one shit to another) & $57(98 \%)$ & $1(2 \%)$ \\
Do you properly clean the storage area before storing new products? & $46(79 \%)$ & $12(21 \%)$ \\
Do you use a sanitizer when washing service utensils? & $58(100 \%)$ & $0(0 \%)$ \\
Do you use a sanitizer when washing fruits & $0(0 \%)$ & $58(100 \%)$ \\
Do you check the shelf life of at the time or delivery/purchase? & $49(84 \%)$ & $9(16 \%)$ \\
\hline
\end{tabular}

\subsection{Consumers' demographics}

Table 5 below shows the demographic characteristics of 93 consumers that participated in the study. In this study there were more male participants $(n=59,63 \%)$ than female participants $(n=34$, $37 \%)$. The mean age of the consumers was (32 \pm 9$)$ and the ages ranged from 18-54. Regarding the occupation of the consumers, there was a wide range of occupations mentioned, except $17 \%$ that was unemployed, while $18 \%$ was self employed and $8 \%$ were not willing to disclose their form of employment. The majority of consumers comprised of police officers (24\%) and taxi drivers (13\%).

Table 5. Demographic characteristics of street food consumers in Maseru

\begin{tabular}{lll}
\hline CHARACTERISTICS & FREQUENCY $(\%)$ & MEAN AND STD DEVIATION \\
\hline GENDER & & $5(63 \%)$ \\
Male & $34(37 \%)$ & $32+9$ \\
Female & & \\
AGE & $1(1 \%)$ \\
OCCUPATION & $2(2 \%)$ \\
Civil servant & $1(1 \%)$ \\
Factory worker & $1(1 \%)$ \\
Farmer & $3(3 \%)$ \\
Government employee & $4(4 \%)$ \\
Health officer & $1(1 \%)$ \\
House keeper & $1(1 \%)$ \\
Inspector at taxi rank & $7(8 \%)$ \\
Musician & $1(1 \%)$ \\
Not specified & $1(1 \%)$ \\
Nurse & $1(1 \%)$ \\
Nurse assistant & $22(24 \%)$ \\
Pharmacist & $7(8 \%)$ \\
Police officer & $1(1 \%)$ \\
Self employed & $4(4 \%)$ \\
Stock manager & $12(13 \%)$ \\
Students & $2(2 \%)$ \\
Taxi driver & $1(1 \%)$ \\
Teller & $16(17 \%)$ \\
Travel consultant & $2(2 \%)$ \\
Unemployment & $1(1 \%)$ \\
Vendor & \\
Volunteer & \\
\hline & \\
&
\end{tabular}

Consumers that participated in this study were asked whether they consume or do not consume street vended food and the reasons thereof. There was a follow up question for those who consume street vended food in order to acquire more information regarding their perceptions and experiences with street vended food. About $6 \%$ of the respondents who do not eat street vended food gave reasons that street food vendors do not practice good hygiene, it is a waste of money to buy street vended foods and others had no specific reasons for not consuming them. 
11 of 11

\subsection{Consumer perceptions and understandings regarding street vended foods}

The questionnaire was fully completed by 87 consumers who mentioned that they consume street vended foods as shown in Figure 1. About $74 \%$ mentioned that they consume street vended foods once in a while and $26 \%$ reported daily consumption. Affordability was highlighted as the main reason for daily consumption of street vended food. However only $10 \%$ consumers reported that they became ill from the consumption of street vended foods and they mentioned that they presented with symptoms such as diarrhea, vomiting, abdominal pains and allergic reactions. Participants also shared recommendations that could possibly improve the street food trade and the frequently mentioned recommendations were that the stalls should be clean and be covered (59\%), clean environment around the stalls (32\%) and proper and adequate cleaning of utensils (32\%).

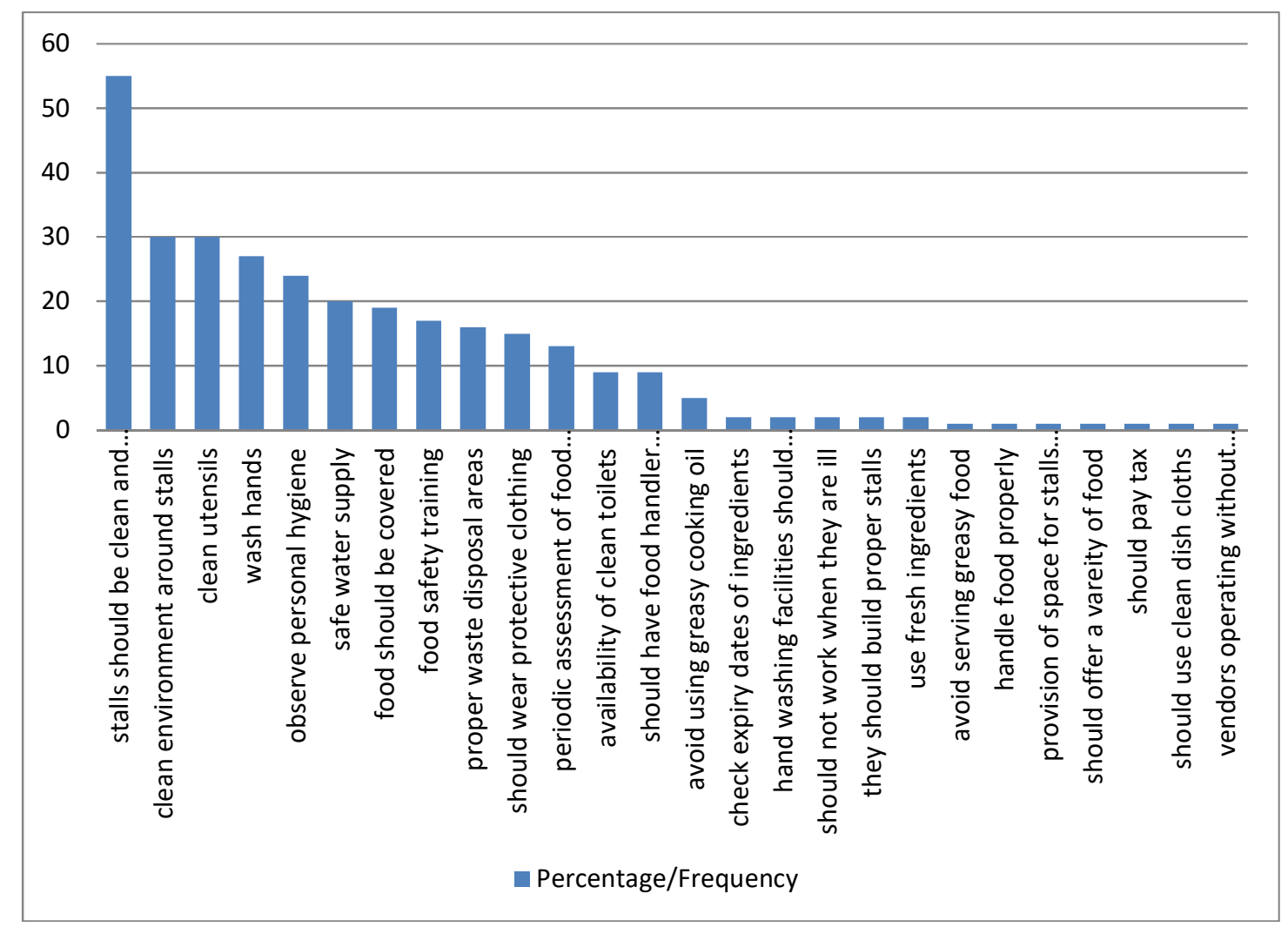

Figure 1. Consumer recommendations regarding areas of improvement in street food vending $(\mathrm{n}=87)$

NOTE: It should be noted that the sum of the frequency percentages is higher than $100 \%$, this is due to the fact that one person could give more than one suggestion

\section{Discussions and Conclusions}

About $70 \%$ of diarrheal diseases in developing countries are said to be of foodborne origin [16]. The focus of the study was to evaluate the food safety knowledge, attitudes and practices of the street food vendors and consumers' perceptions on street vended foods. Many foodborne diseases have been associated with poor handling practices. In this study some of the poor practices exhibited by street food vendors were identified and they included the failure to use protective wear such as gloves, aprons or masks when handling food and some failed to check the expiry date of ingredients 
before buying them. Moreover, there were a higher percentage of vendors operating without food safety training, thus presenting a potential risk that may compromise the safety of food. Some of the identified poor practices include: handling unpackaged food with bare hands, working without an apron, wearing nail polish while preparing food and inadequate cleaning of food storage facilities. Therefore an indication of poor hygiene practices among the street vendors in this study, and similar findings were observed by Kunadu et al., [13] in their study on hygiene practices and knowledge of vendors in Accra, Ghana. However, street food trade in Lesotho has the potential for growth and economic viability given its diversity of consumers. Additionally, it would be ideal to decentralize information regarding food safety, consumer rights and protection and responsibilities. This will be of great value in surveillance programmes and reporting outbreaks. It is therefore further recommended that to improve hygiene, prevention of foodborne illnesses and the enhancement of food vendor effectiveness the following should be optimized: a) local government entities such as the municipality should offer support in terms of infrastructure (construction and allocation of proper stalls, construction of sewage pipelines for disposal of waste water, construction of toilets with adequate hand washing facilities), collection of waste and provision of waste bins/skips and safe and clean water supply; b) street vendors should be provided with food safety training and should be encouraged to avoid preparing food from home, the reason being that preparing food in advance presents an opportunity for microbial growth and contamination. Although this was observed to be a common practice among street food vendors mainly due to lack of refrigeration facilities.; c) food handler certificates, which are a requisition in Lesotho for any persons intending to work in any food establishment should be acquired by all street food handlers before they are allocated a stall or allowed to operate; d) street vendors should be advised against working individually in stalls, but rather in pairs in order to be more efficient. That is, if one of them is focused on the cleaning of the stall and utensils/equipment, the other may be focused on food preparation and serving hence minimizing the chances of cross contamination; e) from the results obtained, all vendors reported that they did not use gloves when handling food. Therefore, the use of protective clothing (clean clothes, aprons and gloves) should be emphasized to the vendors. Akabanda et al., [5] highlighted that the proper use of gloves coupled with hand washing when handling food positively contributes towards the prevention of cross contamination. Judging from the obtained results and observations, the lack of resources such as safe water supply and basic food safety training could be the leading causes of poor knowledge, attitudes and practices amongst the street food vendors. The implementation of all the above-mentioned recommendations is imperative to ensure proper food, personal and environmental hygiene practices which will in turn prevent food borne illnesses.

Acknowledgments: this study was fully funded by the Central University of Technology and the National Research Fund under the Block Grants for Postgraduate studies

Conflict of interests: The authors declare no conflict of interest

\section{References}

1. Rane, S. Street Vended Food in Developing World: Hazards Analyses, Indian J Microbiol 2011. 51(1):pp.100-106. DOI: https://doi.org/10.1007/s12088-011-0154-x

2. Bhat, R.; Alias, A.K.; Paliyath, G. 2012, Progress in Food Preservation, Willey- Blackwell, Oxford, UK. DOI: https://doi.org/10.1002/9781119962045

3. Chukuezi, C.O. Food Safety and Hygienic Practices of Street Food Vendors in Owerri, Nigeria. Studies in Sociology of Science $2010 . \quad 1(1):$ pp.50-57. DOI: http://dx.doi.org/10.3968/j.sss.1923018420100101.005

4. Angelillo, I.F.; Nunzia, M.A.V.; Greco, R.M.; Rito, D. HACCP and Food Hygiene in Hospital: Knowledge, Attitudes, and Practices of Food Services Staff in Calabria, Italy. Infect Control Hosp Epidemiol 2000. 22(6):pp.363-369. DOI: https://doi.org/10.1086/501914 
5. Akabanda, F.; Hlortsi, E.H.; Owusu-Kwarteng. Food safety knowledge, attitudes and practices of institutional food-handlers in Ghana. BioMed Central 2017. 17(40):pp.1-9. DOI: https://doi.org/10.1186/s12889-01603986-9

6. Thanh, T.N.C. Food safety behavior, attitudes and practices of street food vendors and consumers in Vietnam, Masters Thesis, Faculty of Bioscience and Engineering, Ghent University, $2015 . \quad$ Retrieved from: https://lib.ugent.be/fulltxt/RUG01/002/217/245/RUG01-002217245_2015_0001_AC.pdf

7. Nee, S.O.; Sani, N.A. Assessment of Knowledge, Attitudes and Practices (KAP) Among Food Handlers at Residential Colleges and Canteens Regarding Food Safety. SAINS MALAYS 2011. 40(4):pp.403-410. Retrieved from: https://ukm.pure.elsevier.com/en/publications/assessment-of-knowledge-attitudess-and-pr actices-kap-among-food-ha

8. Jain, V. 3D MODEL OF ATTITUDE. IJARMSS 2014. 3(3):pp.1-12. ISSN: 2278-6236

9. Campbell, P.T. Assessing the Knowledge, Attitudes, and Practices of Street Food Vendors in the City of Johannesburg regarding Food Hygiene and Safety. Masters thesis, School of Public Health, University of the Western Cape, South Africa, 2011.

10. Simonson, M.; Maushak, N. 2001. The Handbook of Research for Educational Communications and Technology, instructional Technology and Attitude Change. Iowa State University. Retrieved from: https://nsuworks.nova.edu/cgi/viewcontent.cgi?article=1011\&context=fse_facboo ks

11. Chukwuocha, U.M.; Dozie, I.N.; Amadi, A.N.; Nwankwo, B.O.; Ukaga,C.N.; Aguwa, O.C.; Abanobi, O.C.; Nwoke, E.A. The knowledge, attitudes and practices of food handlers in food sanitation in a metropolis in south eastern Nigeria. East Afr J Public Health 2009. 6(3):pp.240-243. PMID:20803912

12. Ifeadike, C.O.; Ironkwe, O.C.; Adogu, P.O.; Nnebue, C.C. Assessment of the food hygiene practices of food handlers in the Federal Capital Territory of Nigeria. Trop J Med Res 2014. 17(1):pp.10 - 5. DOI: 10.4103/1119-0388.130175

13. Kunadu, A.P.H.; Ofosu, D.B.; Aboagye, E.; Tano-Deborah K. Food safety knowledge, attitudes and self-reported practices of food handlers in institutional food service in Accra, Ghana. Food Control 2016. 69:pp.324-330～DOI:10.1016/j.foodcont.2016.05.11

14. Avanza, P.; Gatchaliam, C.; Ortega, M. Food safety knowledge and practices of street food vendors in a Philippines university campus. Int J Food Sci Nutr 2000. 51(4):pp. 235-246. DOI: https://doi.org/10.1080/09637480050077121

15. Clayton, D.A.; Griffith, C.J.; Price, P.; Peters, A.C. Food handlers' beliefs and self- reported practices. Int $J$ Environ Heal $R$ 2002. 12(1):pp.25-39 DOI: https://doi.org/10.1080/09603120120110031

16. Republic of South Africa, Department of Health. Technical Co-operation Programme (TCP) project on improving street foods in South Africa, , J.H and Anelich, L.E., FAO (TCP/SAF/8924(A)), Oct 2000 